\title{
Resenhas
}

\section{O desejo queima, sangra}

Aparições.

GLANTZ, Margo.

Rio de Janeiro: Contracapa; Belo Horizonte: Autêntica, 2002. 112 p.

O romance Aparições, de Margo Glantz, ${ }^{1}$ traduzido recentemente ao português para a coleção de escritoras latino-americanas editada pela Autêntica (de Belo Horizonte) e pela Contracapa (do Rio de Janeiro), indaga as formas da paixão, tanto sagrada quanto profana, a partir de uma exploração dos níveis do discurso sobre o desejo, o gozo e a perda. Pelo seu uso da língua e sua temática, o romance constitui um verdadeiro desafio à tradução. Será possível dar conta, na escrita, e em outra língua, do que é em si indecente? Aparições faz isso sob a forma de um melodrama desavergonhado em que se filtra 0 inefável. É nesse sentido que a citação literal, oculta no discurso das personagens e narradoras, emerge como uma forma de política textual, uma política de agitação e subversão discursiva, que com palavras voluptuosas nos fala daquilo de que é proibido falar. Isto é, não de sexualidades mais ou menos expostas em diversos suportes comunicativos, mas do gozo de se perder nas paixões mais violentas.

Aparições conta duas histórias de amor ou serão quatro? - em que as vozes de mulheres extraviadas falam os modos da dor e do gozo, sempre esquivos às definições. Sob a forma fragmentária dos 'quadros vivos' que, desde a tradição cristã das estações da cruz, passando por Sade e suas coreografias pornográficas, expõem o indecoro do gozo, surgem no relato os discursos ambíguos do 'Sujeito'. Determinar quem ou o que fala é apenas um dos álibis de Glantz, que nos exorta a atravessar os martírios mundanos de uma narradora cindida e transfigurada sob capas de escrita. A narradora introduz marcas no texto que emergem de maneira sub-reptícia nos discursos dessas mulheres exaltadas, desprovidas de seus donos originais: Sade, Bataille, Sor Juana, Agustín, Ignacio de Loyola, Barthes... Sucessivas mudanças de trajes e emascaramentos se dão através da escrita, fragmentos, 'arrependimentos'2 e equívocos, que conformam o relato plural de uma única paixão: a palavra.

A narrativa latino-americana pensou de maneira recorrente a figura da mulher como 'estrangeira', aquela que fala com outra voz, que traduz 0 alheio. Desde a Malinche traidora e amante, até a figura da cativa na literatura gauchesca e da intrusa borgiana, passando pelas freiras en/clausuradas que sem 'sua voz' falavam a língua de Deus, várias foram as estratégias para contar o que habita o encontro com esse 'outro próximo' que é a mulher. Essa encruzilhada, presente nas Aparições de Glantz, permite refletir para além do discurso literário ou de suas formas representativas, convidando-nos a pensar sobre a heterogeneidade como elemento constitutivo de todo discurso ou relato, e mesmo de todo processo de subjetivação.

A idéia de 'heterogeneidade discursiva', que retomo da análise bajtiniana de Jacqueline AuthierRevuz $z^{3}$ acerca das "heterogeneidades mostradas", remete também a formas de constituição dos/as sujeitos/as. ${ }^{4}$ As heterogeneidades mostradas são intervenções discursivas que por meio de marcas diretas incluem o 'outro' no discurso 'próprio' discurso direto, formas de glosa, aspas, itálicos. A subjetividade falhada da modernidade tardia se expressa da forma mais acabada por meio da inclusão negociada do outro no discurso do 'eu', e digo negociada porque inclui e marca fronteira, isto é, exclui no mesmo ato em que introduz um discurso do outro como 'marcado'. Essa sinalização, ou espécie de amuleto do eu ante sua possível dissolução no heterogêneo, revela-se no relato das paixões que Glantz multiplica, deixando falar livremente "aquela que fala dentro de meu texto..." (p. 7).

A demarcação dos discursos do outro pode ser entendida, assim, como estratégia do eu, como artifício protetor que resguarda o 'Sujeito' sob a ilusão de ser um sujeito autônomo, 
homogêneo e coerente, tanto interna como externamente. Ante a heterogeneidade mostrada, sei quem fala, sei o que digo, como o digo, sou o observador da minha linguagem, 'sou juiz do meu falar'. No entanto, a heterogeneidade aplacada, 'duplo perfeito' do eu que escapa às marcas discursivas, ameaça de inconsistência o relato do eu-unificado e exige um nome próprio para o que é do outro: "Só ao nomeá-la saberei quem sou" (p.18).

A/s narradora/s, que "é Legião" - uma e múltipla como o divino e o demoníaco -, confunde/m-se o tempo todo com a/s protagonista/s da/s história/s. Juntas contam a história como se fosse a história de outras (Sor Lugarda e Sor Teresa Juana, a amazona que aparece e desaparece no quadro, a menina), todas elas mulheres ligadas à palavra, mas que se dizem com palavras que não lhes pertencem: as palavras das escrituras, a palavra de Deus, as palavras da ordem. Como diz a escritora no romance: "Um objeto que fala da perda, da destruição, da desaparição de objetos, não fala de si, fala de outros. Será que também os abarcará?" (p. 18).

Essa voz que nomeia outras, que é ordenada por sua vez por uma voz masculina ou masculinizada - que 'se ordena' e 'se obedece' -, nos fala da produtividade do 'eu', desmembrando-o e mostrando as filtrações, as faltas, os pecados, as marcas e transfigurações que afetam os corpos, revelando o que habita na voz: "... me oculto sob a aparência e a figura de uma mulher" (p. 28).

A escrita de Glantz nos remete de maneira incessante a esse paradoxo que a teoria feminista não se cansa de assinalar: a da constituição impossível de um/a sujeito/a unificado/a em uma identidade pessoal coerente e em uma experiência intransferível. A sucessão 'corpo/ gênero/desejo/prática sexual' é uma maneira de nomear o que se constitui sempre como heterogeneidade, não mais dos 'papéis sociais' a desempenhar em momentos alternados e, no entanto, coerentes entre si, mas do que 'somos', a forma sob a qual 'aparecemos' ubiquamente. Surge ali a figura da amazona sobre a qual fora pintada outra figura - masculina - que adota posições femininas ao montar, prestando-se a equívocos. Essa representação apagada e enigmática nos observa e se esconde em algum lugar 'fora da moldura', assinalando a falsidade do que mostra:

"Pronunciar e expor a alteridade dentro da norma [...] expõe o fracasso da norma para exercer $o$ alcance universal que representa, expõe o que poderíamos figurar como a prometedora ambivalência da norma [...] a enunciação se transformou numa cena de conflito..."

Dominar a linguagem, que é sempre cenário do conflito na fundação do 'eu', não só implica se saber privada/o de ferramentas próprias, mas também impõe a necessidade de se valer das 'armas do senhor' para lutar em um terreno impróprio. Esse confinamento antecipado se reforça para as mulheres, posto que seu universo simbólico se encontra subsumido a construções dominantemente masculinas. No entanto, pensar o discurso na perspectiva de sua heterogeneidade implica considerar o 'Sujeito' mesmo como contingente, posto que ninguém se encontra a salvo de sua emergência, como adverte a personagem da escritora: "Aqueles que nunca estiveram tão despojados de si mesmos que atirem a primeira pedra!" (p. 31).

E essa pedra, a palavra lançada gozosamente na escrita privada, é também o espaço de aparição pública que as mulheres exigiram para si com mais ardor nas formas mais diversas da autobiografia, da carta, da confissão. Talvez porque estivesse em jogo ali a dimensão do espaço privado que mais se conecta com a aparição no espaço público: o corpo exposto, comprometido na sexualidade e na escrita, tal como as palavras das freiras enclaustradas expostas ao juiz do confessor, correndo riscos mortais no momento em que se materializam. Como diz Octavio Paz a propósito de Sor Juana, enquanto o silêncio “... é indizível, expressão sonora do nada. O calar é significativo". ${ }^{6}$ Esse calar, essa ausência de palavra pública, expressa aquilo que não se pode dizer, não o nada.

São as palavras e os discursos que encarnam a política que se inscreve nos corpos, "com prazer e com dor", como também adverte Butler acerca da assunção do gênero, ${ }^{7}$ palavras que Glantz transforma em elementos pungentes que mortificam os sujeitos do discurso. "Você gostaria de estar sempre morrendo desse mal" (p. 36).

Nesse sentido, uma política textual de agitação que se serve do recurso às palavras de outros sem marcas de sua intrusão correspondese com uma política sexual de deslizamento, contaminação e desajuste. Aparições nos fala do escândalo da proliferação narrativa dos corpos, remetendo-nos insistentemente à duplicação do desejo que, como o amor, arde mais tenuemente em leito de abrolhos, e é menos tormentoso quando escrito com 'outro' corpo.

\footnotetext{
1 Margo Glantz é escritora, ensaísta e crítica literária mexicana. Seu romance Apariciones foi traduzido em 2002 pela escritora argentino-brasileira Paloma Vidal.
} 
2 A palavra 'arrependimento', do italiano pentimento, refere-se aqui à modalidade usual na arte renascentista que consistia no 'apagamento' de uma pintura para reutilizar o suporte como base para uma nova obra. Esse procedimento permanecia oculto até que com a passagem do tempo as capas de tinta superiores desapareciam, dando lugar à re-aparição da pintura anteriormente 'apagada'. Com freqüência, seu uso somente é descoberto em processos de restauração e limpeza da obra, séculos depois.

${ }^{3}$ AUTHIER-REVUZ, Jaqueline. "Hétérogénéité/s discursive/ s". Langages, Paris: Larousse, n. 73, p. 98-111, mars 1984. ${ }^{4}$ Ainda que a palavra 'sujeito' não tenha forma feminina em castelhano, prefiro assinalá-la em referência a essa dimensão escondida da subjetividade sob a forma 'masculina' universalizada pelo uso gramatical. Assim, 'sujeita' implica tanto a condição de subjetivação, no sentido moderno do termo, quanto a condição de sujeição à ordem social e simbólica, inerente ao processo de subjetivação.

${ }^{5}$ BUTLER, Judith. "Soberanía y actos de habla performativos" (trad. Ana Romero). Accion Paralela. Revista de Ensayo, Teoría y Crítica del Arte Contemporáneo, s/f. Downloaded de: http:// www.accpar.org/numero4/index.htm. (Título original: "Sovereign Performatives". In: BUTLER, Judith. Excitable Speech: A Politics of the Performative. New York:
Routledge, 1997. Cap. 2, p. 71-102)

${ }^{6} \mathrm{Paz}$, Octavio. "Homenaje a Sor Juana Inés de la Cruz en su Tercer Centenario (1651-1695)". Revista Sur, n. 206, p. 29-40, dic. 1951.

${ }^{7}$ Judith Butler pensa o gênero como uma atuação dramática do corpo que não se refere a nenhuma essência preexistente ou manifesta no próprio corpo. A atuação do gênero é uma espécie de estratégia de sobrevivência oculta aos olhos de seus atores, um 'fetiche' que confunde as categorias biológicas e culturais. Esse libreto ritualizado é sempre repetido de forma paródica, já que não há um 'original' a reproduzir. O corpo é generizado nessa atuação, isto é, é investido com as marcas do 'seu' gênero, exigindo uma correspondência, uma coerência entre o corpo-sexo e o corpo-gênero. Ver: BUTLER, Judith. "Actos performativos y constitución del género: un ensayo sobre fenomenología y teoría feminista". Debate Feminista, México, v. 18, p. 296-314, oct. 1998; e BACCl, Claudia; FERNÁNDEZ, Laura; OBERTI, Alejandra. "De injusticias y anacronismos". El Rodaballo. Revista de Política y Cultura, Buenos Aires, n. 11/12, p. 86-92, 2000.

Claudia Bacci Universidad Nacional de Buenos Aires 